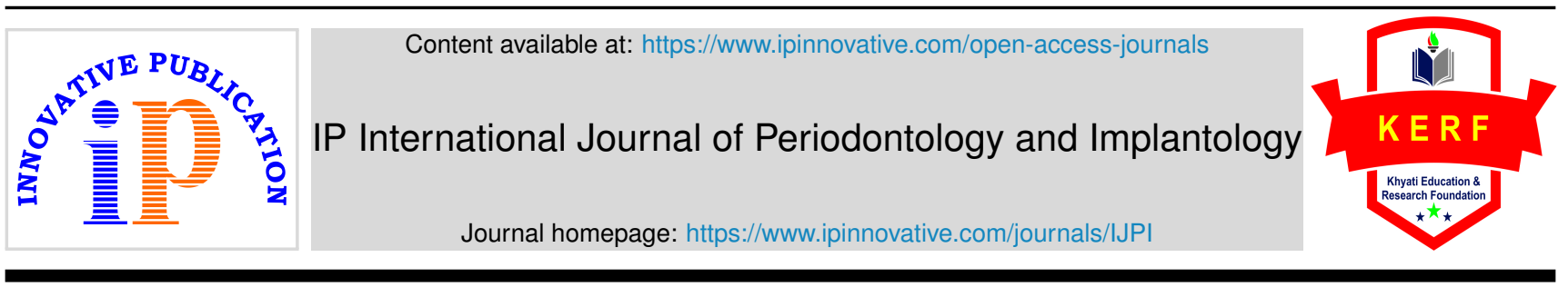

\title{
Editorial
}

\section{Current and future prospective of marine based biomaterials in periodontal regeneration}

\author{
Nebu George Thomas ${ }^{1, *}$ \\ ${ }^{1}$ Dept. of Periodontics, Pushpagiri Collrge of Dental Sciences Perumthuruthy, Tiruvalla, Kerala, India
}

\section{A R T I C L E I N F O}

Article history:

Received 05-12-2020

Accepted 12-12-2020

Available online 24-12-2020
(C) This is an open access article distributed under the terms of the Creative Commons Attribution License (https://creativecommons.org/licenses/by/4.0/) which permits unrestricted use, distribution, and reproduction in any medium, provided the original author and source are credited.
Main objective of periodontal tissue engineering is to regenerate the tooth supporting Tooth loss can be due to trauma, congenital anomalies, cyst and periodontal diseases. Two distinct aims in periodontal tissue engineering strategies are towards the formation of new alveolar bone and connective tissue (cementum and periodontal ligament). Current therapies for periodontal regenerative therapies include root conditioning, bone grafting and guided tissue regeneration.

Bone grafting is one of the most commonly used surgical methods to augment periodontal defects. Autologous bone is still being considered as the gold standard. However, the concerns of limitedsupply and donor site complications still exist. Bone allografts dominantly share the second higher option for periodontal regeneration but their limitation is inferior healing was and potential for transmission of disease and other infective agents.

Due to its rich biodiversity, marine environment yields structures with immense potential for biomedical application. These bio molecules offer many applications in cartilage and bone tissue engineering, dental tissue regeneration, wound healing and local drug delivery system With the help of continuous researches in the field of marine bio environment, an array of marine natural products has been established and they form dominant components of pharmaceuticals and tissue engineered constructs. Thus they merge as valuable agents for periodontal regeneration and for alveolar ridge preservation. Marine sources are abundant resource for collagen, chitosan and bioceramics. Threedimensional (3D) bioprinting, an emerging field in tissue engineering where additive manufacturing technology was used, in which cell-laden bioinks are deposited in a layer-bylayer fashion, shows promise for meeting the requirements for reconstructing complex periodontal tissues. In 3D bioprinting, as bioinks contain living cells and biomaterials are key components

Among various marine-origin macromolecules, alginate, carrageenan, chitosan, HA, collagen, and gelatin have emerged as marine based biomaterials for 3D bioprinting of regenerative medicine. Marine biomaterials satisfy most requirements of 3D bioprinting, such as printability, mechanical integrity, and biocompatibility. Since sea is a huge reservoir of natural biopolymers, raw marine materials will be a new resource for 3D bioprinting.

\section{Author biography}

Nebu George Thomas, Professor

Cite this article: Thomas NG. Current and future prospective of marine based biomaterials in periodontal regeneration. IP Int J Periodontol Implantol 2020;5(4):133-133.

\footnotetext{
* Corresponding author.

E-mail address: nebugt@gmail.com (N. G. Thomas).
} 